\title{
Perinatal Outcomes in Pregnant Women with Anemia of Various Geneses
}

\author{
Victor E. Radzinsky, $\mathrm{PhD}, \mathrm{ScD}^{1}$; Bakhtykei M. Gasanova, $\mathrm{PhD}^{1}$; \\ Miroslava L. Polina, $\mathrm{PhD}^{2 *}$; Natalya I. Douglas, $\mathrm{PhD}, \mathrm{ScD}^{3}$; Irina S. Bulshiy, $\mathrm{PGS}^{3}$; \\ Fatima I. Chotchayeva ${ }^{4}$; Tatyana V. Dedy, $\mathrm{PhD}^{5}$ \\ ${ }^{1} R U D N$ University, Moscow, Russia \\ ${ }^{2}$ Women's Health Medical Center, Moscow, Russia \\ ${ }^{3}$ M. K. Ammosov North-Eastern Federal University, Yakutsk, Russia \\ ${ }^{4}$ Republican Perinatal Center, Cherkessk, Russia \\ ${ }^{5}$ Federal Medical-Biological Agency, Moscow, Russia
}

\begin{abstract}
Modern methods for diagnosing disorders of iron metabolism (ferritin, C-reactive protein) in iron deficiency anemia (IDA) and anemia of chronic diseases (ACD) contribute to the identification of metabolic characteristics that negatively affect the motherplacenta-fetus system.

The biological response to hypoxia varies in anemia of different geneses: depletion of iron depot on the background of chronic infectious and inflammatory processes is accompanied by more obvious homeostasis disorders. Excessive activity of the peroxidase system (increase in prooxidant factors - malondialdehyde, catalase of blood serum and red blood cells, sulfhydryl groups) explains the large frequency of gestational complications and perinatal diseases in ACD women, such as morphofunctional immaturity, hypoxic-ischemic lesion of the central nervous system of newborns, and infectious and inflammatory diseases.

The degree of ante- and perinatal well-being in conditions of iron deficiency, accompanied by a violation of the molecular mechanisms of protein synthesis, depends on the activity of adaptive homeostatic mechanisms of the mother-placenta-fetus system. The strategy to reduce adverse perinatal outcomes includes identification of abnormal metabolism predictors with the expansion of the scope of examination in groups with high infectious risk, further monitoring of risk cases, and pathogenetic therapy. (International Journal of Biomedicine. 2020;10(3):241-246.)
\end{abstract}

Key Words: iron deficiency anemia $\bullet$ anemia of chronic diseases $\bullet$ outcomes $\bullet$ oxidative stress

\section{Abbreviations}

ACD, anemia of chronic diseases; AOD, antioxidant defense; CRP, C-reactive protein; CP, chronic pyelonephritis; ESR, erythrocyte sedimentation rate; ID, iron deficiency; IDA, iron deficiency anemia; LPO, lipid peroxidation; MDA, malondialdehyde; MCV, mean corpuscular volume; MCHC, mean corpuscular hemoglobin concentration; MCH, hemoglobin amount per RBC; PI; placental insufficiency; PhP, physiological pregnancy; RBC, red blood cell; SI, serum iron.

\section{Introduction}

Iron deficiency (ID) is a global public health problem affecting $10 \%-90 \%$ of pregnant women, from $5.4 \%$ in developed

"Corresponding author: Miroslava L. Polina, PhD. Women's Health Medical Center, Moscow, Russia, e-mail: polina.ml@mail.ru countries to more than $80 \%$ in developing ones. ${ }^{(1-3)}$ The prevalence of anemia is heterogeneous in various regions of the Russian Federation. In the Republic of Sakha (Yakutia) (RS(Y)) in 2018, the frequency of anemia among diseases that preceded or occurred during pregnancy was higher than the all-Russian indicator $(\mathrm{RS}(\mathrm{Y})-42.3 \%$; RF-35.6\%). This discovery requires deep fundamental research on the nutritional characteristics and micronutrient-macronutrient status of pregnant women. 
Despite the downward tendency of anemia in the Karachay-Cherkess Republic over the past decade, medical organizational approaches are advancing in order to improve the health of pregnant women and perinatal outcomes.

The development of anemia is associated with socioeconomic conditions, protein deficiency in the diet, lack of essential vitamins and minerals (A, $\mathrm{B}_{12}$ and folic acid), and chronic blood loss. ${ }^{(4)}$ The biological role of iron in the body is multifaceted: oxygen transfer by red blood cells, providing redox processes, peroxidation reactions, synthesis of steroid and thyroid hormones, DNA, enzyme activity regulation. ${ }^{(5)}$

High frequency of gestational complications, fetal hypotrophy, asphyxia and pathological immaturity of newborns in anemia are considered to be the consequences of hemic and tissue hypoxia.

The potential mechanisms of the effect of ID on the body of the pregnant woman and the fetus differ depending on the genesis of the anemia, on the development of oxidative stress, and on disorders of the systemic response to inflammation and infection.

Modern methods of diagnosing anemia contribute to the identification of its types, in relation to metabolic characteristics affecting angiogenesis, placentation and antenatal development of the fetus; however, opinions are ambiguous. $^{(5)}$

Reducing gestational complications and perinatal morbidity is not possible in the absence of clear criteria for differentiating IDA and ACD, for which therapy with ironcontaining drugs has been proved inefficient. ${ }^{(6)}$

Differentiation of the genesis of anemia from an early date is crucial in order to prevent negative pregnancy outcomes and preserve the cognitive potential of the fetus. The key role in the selection of treatment tactics is determined by ID type (absolute or functional), with impaired distribution on the background of chronic inflammatory diseases (intestines, liver, kidneys), and obesity.

Risks associated with ID hypodiagnostics on the background of a systemic inflammatory reaction, in connection to pregnancy outcomes, are underestimated.

The accompanying inflammatory process in the body distorts the iron metabolic pattern: functional deficiency with its unchanged total content occurs due to sequestration in the reticuloendothelial system.

ACD (ICD D63.8) appears to be the pathogenetic response of the body to a long-term infectious, inflammatory or autoimmune process, with impaired erythroid proliferation predecessors. ${ }^{(6)}$ "Infect anemia" of pregnant women is a special case of ACD ( $4 \%$ of all anemia), resistant to iron treatment. ${ }^{(5)}$

The diagnostic value of hematological and biochemical parameters for various anemia geneses is debatable.

A common criterion for anemia in the first trimester of pregnancy was found to be a hemoglobin level less than 110 $\mathrm{g} / \mathrm{l}^{(4)}$ Risk of adverse outcomes for mother, fetus and newborn appears, according to a meta-analysis, at a hemoglobin level of less than $110-100 \mathrm{~g} / \mathrm{l}$ in the first two trimesters of pregnancy, ${ }^{(7)}$ according to other sources - in the presence of severe anemia. ${ }^{(8)}$

The diagnostic value of the parameters of the general blood test (MCV [the average $\mathrm{RBC}$ size], $\mathrm{MCH}$, color index) as isolated IDA markers is disputed ${ }^{(9)}$ in contrast to the greater sensitivity of MCHC. ${ }^{(10)}$

The gold standard for IDA is a decrease in ferritin less than $30 \mathrm{mcg} / \mathrm{l}$, regardless of hemoglobin and SI concentrations ${ }^{(4)}$ Additionally noted is erythrocytes hypochromia, a decrease in the average hemoglobin content in an erythrocyte, SI less than 15 $\mathrm{ng} / \mathrm{ml}$, a tendency to leukopenia, and an increase in the ESR. ${ }^{(11)}$

The combination of ID and a chronic inflammatory process complicates the assessment of iron metabolism. ${ }^{(6)}$ Pregnant women with $A C D$ are distinguished by ferritin variability from normal to elevated indices as protein of acute inflammation phase. ${ }^{(12)}$ The informative value of CRP content in the diagnosis of ID among pregnant women with autoimmune and inflammatory diseases is superior to transferrin and its soluble receptor, hepcidin. ${ }^{(13)}$

Preclinical diagnosis of PI among pregnant women with anemia is considered possible on the basis of the assessment of individual parameters of homeostasis in its various types, ${ }^{(5,14)}$ especially in groups with high infectious risk.

The LPO activation in PhP is explained by the need for the accumulation of "strategic" iron resources. ${ }^{(15)}$ Oxidative stress during pregnancy is caused by increased metabolism; lack of a number of factors (catalase, glutathione peroxidase and glutathione transferase) requires inhibiting the synthesis of hydroperoxides. ${ }^{(15)}$

The consistency of the mechanisms for suppressing excess hydroperoxides affects the prognosis of consequences of anemia for the embryo/fetus and placental-fetal interaction.

The specificity of LPO-activity/AOD-processes in various types of anemia has been poorly studied. ${ }^{(16-18)}$

Ideas of anemia types among pregnant women allow us to address the pathogenetic therapy of the diseases. Prescribing iron preparations resulted in a decrease in anemia by $70 \%$, ID - by $57 \%$ until the time of childbirth. ${ }^{(19)}$ On the contrary, the consequences of unreasonable ferrotherapy in normal or elevated levels of ferritin include competitive binding of iron by microbial and tumor cells, development of oxidative stress due to an excess of free radicals, endothelial dysfunction, and gestational diabetes mellitus. ${ }^{(20,21)}$

The effect of metabolic disorders in IDA and ACD on perinatal outcomes and the real prognostic value of peroxidation markers remain unclear. ${ }^{(12,22)}$

The general objective of the current study was to evaluate the effect of homeostasis features of iron metabolism and oxidative status among pregnant women with anemia of various geneses on perinatal outcomes.

\section{Materials and Methods}

The study cohort included pregnant women with IDA ( $\mathrm{n}=286)$ and ACD ("infect anemia") $(\mathrm{n}=184)$. Healthy pregnant women made up the control group $(n=34)$. Written informed consent was obtained from all participants.

Inclusion criteria: single-child progressive pregnancy, the presence of anemia before planning pregnancy, the informed consent of a woman to use biological material for scientific purposes.

Research methods included the assessment of a general blood test (RBCs, hemoglobin, platelets, white blood cells, 
lymphocytes, monocytes, ESR, MCV, MCH, SI, CRP, ferritin (ELISA-ferritin test system (St. Petersburg)), total protein, and pro- and antioxidant factors (catalase of blood serum and RBCs, sulfhydryl groups, ceruloplasmin, and MDA in blood serum).

In IDA, anemia treatment included 100-300 mg ferrous iron per day, in ACD - identification and treatment of subclinical infectious and inflammatory diseases, and urogenital infections (antibiotic therapy, antioxidants, total tocopherols, polyunsaturated fatty acids, and probiotics). The general recommendation for pregnant women with anemia is folate supplementation (400-800 mcg per day), vitamins, minerals, and diet (protein, oligopeptides).

Statistical analysis was performed using the Statistica 10 software package (Stat-Soft Inc., USA). The normality of distribution of continuous variables was tested by the ShapiroWilk test. Baseline characteristics were summarized as frequencies and percentages for categorical variables and as mean (M) and standard error of the mean (SEM) for continuous variables. Student's unpaired t-test was used to compare average values for data with normal distribution. Group comparisons with respect to categorical variables are performed using chisquare tests with Yates correction or, alternatively, Fisher's exact test when expected cell counts were less than 5. A probability value of $P \leq 0.05$ was considered statistically significant.

\section{Results and Discussion}

The average age of participants with ACD was $26.8 \pm 3.2$ years, IDA $-27.3 \pm 4.1$ years, without significant intergroup differences. Data on past illnesses of participants with IDA and ACD are presented in Table 1.

Table 1.

Chronic diseases of pregnant women with anemia of various geneses

\begin{tabular}{|l|c|c|c|}
\hline \multicolumn{1}{|c|}{ Diseases } & $\begin{array}{c}\text { IDA } \\
(\mathrm{n}=286)\end{array}$ & $\begin{array}{c}\text { ACD } \\
(\mathrm{n}=184)\end{array}$ & $P$-value \\
\hline Sinusitis & $16(5.6)$ & $27(14.7)$ & 0.002 \\
\hline $\begin{array}{l}\text { Rhinitis. nasopharyngitis } \\
\text { and pharyngitis }\end{array}$ & $33(11.5)$ & $66(35.9)$ & 0.0005 \\
\hline Respiratory diseases & $21(7.3)$ & $45(24.4)$ & 0.0005 \\
\hline Kidney diseases & $41(14.3)$ & $67(36.4)$ & 0.0005 \\
\hline $\begin{array}{l}\text { Inflammatory diseases } \\
\text { of the female pelvic organs }\end{array}$ & $78(27.4)$ & $99(53.8)$ & 0.0005 \\
\hline
\end{tabular}

A number of chronic diseases (sinusitis $(P=0.002)$, upper $(P=0.0005)$ and lower $(P=0.0005)$ respiratory tract diseases, $\mathrm{CP}(P=0.0005))$ identified pregnant women with $\mathrm{ACD}$ as a group with a high infectious risk.

Inflammatory diseases of the female pelvic organs were characteristic of almost half of the women with ACD and only a quarter with IDA $(P=0.0005)$.

Pregnancy in ACD women was more often complicated by gestational pyelonephritis $(P=0.0009), \mathrm{CP}$ exacerbation $(P=0.0005)$, and acute respiratory infections $(P=0.0005)$, compared with IDA women (Table 2).
Table 2.

Pregnancy complications in anemia of various geneses

\begin{tabular}{|l|c|c|c|}
\hline \multicolumn{1}{|c|}{$\begin{array}{c}\text { Pregnancy complications } \\
\text { and diseases }\end{array}$} & IDA & ACD & $P$-value \\
\hline Gestational pyelonephritis & $24(8.4)$ & $38(20.6)$ & 0.0009 \\
\hline Exacerbation of CP & $11(3.8)$ & $43(23.4)$ & 0.0005 \\
\hline Sonographic signs of fetal infection & $18(6.3)$ & $39(21.2)$ & 0.0005 \\
\hline Acute respiratory viral infections & $21(7.3)$ & $34(18.5)$ & 0.001 \\
\hline
\end{tabular}

Sonographic signs of fetal infection were noted three times more often in $\operatorname{ACD}(P=0.001)$.

A study of the hematological parameters of pregnant women showed a greater decrease in $\mathrm{MCV}$ and $\mathrm{MCH}$ in the $\mathrm{ACD}$ group in contrast to the average hemoglobin values (Table 3 ).

Table 3.

Hematological parameters of pregnant women with anemia of various geneses

\begin{tabular}{|l|c|c|c|c|}
\hline \multicolumn{1}{|c|}{ Parameters } & $\begin{array}{c}\text { IDA } \\
(1)\end{array}$ & $\begin{array}{c}\text { ACD } \\
(2)\end{array}$ & $\begin{array}{c}\text { Control } \\
\text { group (3) }\end{array}$ & \multicolumn{1}{|c|}{$P$-value } \\
\hline *Erythrocytes, $10^{12} / 1$ & $3.37 \pm 0.05$ & $3.44 \pm 0.04$ & $3.9 \pm 0.05$ & $\begin{array}{l}\mathrm{P}_{1-3}=0.03 \\
\mathrm{P}_{2-3}=0.005\end{array}$ \\
\hline Hemoglobin, g/1 & $95.4 \pm 6.4$ & $106.8 \pm 5.4$ & $136.6 \pm 5.3$ & $\begin{array}{l}\mathrm{P}_{1-3}=0.002 \\
\mathrm{P}_{2-3}=0.03\end{array}$ \\
\hline *Platelets, 109/1 & $248.5 \pm 11.6$ & $218.5 \pm 9.6$ & $248.5 \pm 11.6$ & $\mathrm{P}>0.05$ \\
\hline MCV, fl & $83.5 \pm 1.2$ & $92.5 \pm 1.1$ & $98.5 \pm 1.4$ & $\begin{array}{l}\mathrm{P}_{1-2}=0.005 \\
\mathrm{P}_{2-3}^{1-3}=0.03\end{array}$ \\
\hline MCH, pg & $28.4 \pm 0.5$ & $31.3 \pm 0.52$ & $33.3 \pm 0.4$ & $\begin{array}{l}\mathrm{P}_{1-2}^{1-2}=0.04 \\
\mathrm{P}_{2-3}^{1-3}=0.03\end{array}$ \\
\hline *Leukocytes, $10^{9} / 1$ & $5.6 \pm 0.8$ & $6.2 \pm 1.1$ & $5.2 \pm 0.8$ & $\mathrm{P}>0.05$ \\
\hline
\end{tabular}

*- The content of leukocytes and platelets in groups with anemia did not significantly differ from that in healthy pregnant women.

The results of hematological and biochemical parameters of pregnant women with anemia of various geneses are presented in Table 4.

Table 4.

The results of studies of iron metabolism and pro-inflammatory markers among women with anemia of various geneses

\begin{tabular}{|l|c|c|c|}
\hline \multicolumn{1}{|c|}{ Hematological parameters } & IDA & ACD & $P$-value \\
\hline Ferritin reduction, mcg/l & $286(100.0)$ & 0 & - \\
\hline Normal ferritin level, mcg/l & 0 & $34(18.5)$ & - \\
\hline $\begin{array}{l}\text { Increased ferritin level, } \\
\text { mcg/l }\end{array}$ & 0 & $150(81.5)$ & - \\
\hline C-reactive protein, mg/l & 0 & $184(100.0)$ & - \\
\hline Lymphocytosis & $28(9.8)$ & $54(29.3)$ & 0.0005 \\
\hline Monocytosis & $23(8.0)$ & $42(22.8)$ & 0.0005 \\
\hline ESR increase, $\mathrm{mm} / \mathrm{h}$ & $13(4.5)$ & $27(14.7)$ & 0.0009 \\
\hline Serum iron, mcmol/1 & $7.8 \pm 2.6$ & $12.4 \pm 4.2$ & 0.001 \\
\hline Total protein, g/l & $74.6 \pm 4.2$ & $69.4 \pm 5.3$ & 0.03 \\
\hline
\end{tabular}


Unreasonable reliance on hemoglobin and SI exclusively in IDA diagnosis confirms the low ferritin with MCV and $\mathrm{MCH}$ in comparison with "infect anemia." ${ }^{23)}$ True ID with a decrease in $\mathrm{MCV}(<80 \%)$ and ferritin $(<12 \mathrm{ng} / \mathrm{ml})$, as well as SI $(<40 \mathrm{mcg} / \mathrm{dl})$, was also confirmed by other authors. ${ }^{(24)}$

The depletion of iron reserves during ACD was accompanied by a range of ferritin from normal (18.5\%) to elevated $(81.5 \%)$, due to the redistribution of abnormal microbiome of various loci of the body on the background of chronic inflammatory processes.

Iron sequestration in macrophages and hepatocytes reflects the protective mechanism, which reduces competition for a biological resource between pathogens and the body of a pregnant woman.

The normal level of ferritin is explained by the physiological increase in acute phase proteins. ${ }^{\left({ }^{6}\right)}$ The standard of ACD is a pro-inflammatory shift of the leukocyte formula in some cases (lymphocytosis, monocytosis and increased ESR), and CRP due to tissue alteration. An inflammatory reaction with CRP $>6 \mathrm{ng} / \mathrm{ml}$ in $52.2 \%$ of women with anemia versus $28.8 \%$ in its absence was noted by Mburu et al. ${ }^{(25)}$

Reactive changes in erythropoiesis and iron metabolism during inflammation, infection, or autoimmune disease ${ }^{(26)}$ indicate a difference in the pathogenetic mechanisms of iron deficiency in IDA and ACD.

A significant protein deficiency, along with low hemoglobin in the presence of normal and high ferritin content, means a violation of the activity of the iron transport chain, its release from macrophages and delivery to tissues. ${ }^{(6,20)}$

SI content was found to be reduced in IDA and corresponded to reference values in the group with $\mathrm{ACD}$ $(P=0.001)$.

The analysis of the activity of free radical oxidation processes indicated an increased production of a number of free radical molecules in ACD (Table 5).

\section{Table 5.}

Pro- and antioxidant factors in samples of pregnant women with anemia of various geneses

\begin{tabular}{|c|c|c|c|c|}
\hline Parameters & $\begin{array}{c}\text { IDA } \\
(1)\end{array}$ & $\begin{array}{c}\mathrm{ACD} \\
(2)\end{array}$ & $\begin{array}{l}\text { Control } \\
\text { group (3) }\end{array}$ & $P$-value \\
\hline $\begin{array}{l}\text { Malonic dialdehyde, } \\
\mathrm{mcmol} / 1\end{array}$ & $1.3 \pm 0.1$ & $1.7 \pm 0.1$ & $1.2 \pm 0.4$ & $\begin{array}{l}P_{1-3}=0.005 \\
P_{2-3}=0.01\end{array}$ \\
\hline $\begin{array}{l}\text { Erythrocyte catalase } \\
\text { activity, mkat/1 }\end{array}$ & $74.9 \pm 1.4$ & $87.4 \pm 2.7$ & $74.7 \pm 0.9$ & $\begin{array}{l}P_{1-3}=0.001 \\
P_{2-3}=0.02\end{array}$ \\
\hline $\begin{array}{l}\text { Serum catalase } \\
\text { activity, mkat/1 }\end{array}$ & $14.8 \pm 1.5$ & $29.6 \pm 2.4$ & $15.7 \pm 0.5$ & $\begin{array}{l}P_{1-3}=0.001 \\
P_{2-3}=0.005\end{array}$ \\
\hline Ceruloplasmin, mg/l & $369.8 \pm 12.5$ & $406.3 \pm 14.1$ & $366.9 \pm 13.5$ & $P>0.05$ \\
\hline $\mathrm{SH}$-groups, mmol/1 & $13.3 \pm 0.4$ & $17.2 \pm 1.3$ & $12.4 \pm 0.4$ & $\begin{array}{l}P_{1-3}=0.005 \\
P_{2-3}=0.01\end{array}$ \\
\hline
\end{tabular}

The decrease in compensatory abilities of the body on the background of excessive production of prooxidant factors (MDA, SH-groups, catalase of blood serum and RBCs) among pregnant women with ACD corresponds to the state of endointoxication associated with obstetric complications. ${ }^{(27)}$
The prevalence of free radical reactions should be regarded as homeostasis failure caused by functional defectiveness of iron antioxidant enzymes.

The concentration of one of the main antioxidants of ceruloplasmin, glycoprotein of the alpha-2-globulin blood fraction did not significantly increase, confirming the limited immune reserves in the group with "infect anemia." Such observations allow us to note that the imbalance of pro- and antioxidant factors with the development of oxidative stress during ACD is accompanied by depletion of the erythroid germ.

The reduction of the number of factors providing protection from the damaging effects of hydroperoxides was accompanied by an increase in redox cell potential.

The value of hematological and biochemical studies for the preclinical diagnosis of PN among pregnant women with anemia was $100 \%$ for ACD and $63.6 \%$ IDA.

The morphological basis of PI in anemia of various geneses proves to be angiopathy of the uterine vessels, revealed in studies of the placental bed. ${ }^{(5,28)}$ The lack of complete transformation of the spiral arteries, then the utero-placental, with the abnormal development of the villous tree, affects the functional activity of the utero-fetalplacental complex of pregnant women with anemia. Universal metabolic reactions with ID among pregnant women with anemia of various geneses show that its participation is limited in the physiological reactions of the body and the other plastic resources necessary for fetal growth. ${ }^{(29)}$

In groups with anemia, urgent birthgiving was $82.3 \%$, premature $-17.6 \%$, and caesarean section $-12.8 \%$.

Newborns from mothers with ACD differed slightly in body weight $-2970 \pm 280 \mathrm{~g} / \mathrm{l}$ versus $2850 \pm 140 \mathrm{~g} / \mathrm{l}$ in the IDA group $(P=0.07)$. Obviously, non-replenished ID, even with high compensatory resources of the placenta, leads to a deterioration of placental angiogenesis, fetal ischemia and growth restriction, and newborns of low weight. ${ }^{(30)}$ The number of newborns in the groups of women with anemia who needed to be transferred to the intensive care unit (ICU) was $16.2 \%$; in the ACD group it was almost three times higher (24.4\% and $8.7 \%$ ) than in the IDA group: however, without statistically significant differences. The number of children requiring nursing was slightly higher in the ACD group than in the IDA group (24.4\% versus $11.5 \%$; $\left.\chi^{2}=4.3, P=0.04\right)$.

Anthropometry of newborns from mothers with anemia was inferior to the parameters of healthy ones, without affecting their viability, with a greater need for intensive care in the ACD group. ${ }^{(29)}$ In groups with anemia, $8.5 \%$ of newborns had a small gestational period at birth, $23.6 \%$ had hypotrophy (Table 6).

\section{Table 6.}

Perinatal morbidity in groups of women with anemia of various geneses

\begin{tabular}{|l|c|c|c|}
\hline \multicolumn{1}{|c|}{ Newborns' diseases } & IDA & ACD & $P$-value \\
\hline Hypotrophy & $59(20.6)$ & $49(26.6)$ & 0.2 \\
\hline Infectious and inflammatory diseases & $14(4.9)$ & $27(14.7)$ & 0.001 \\
\hline Morphofunctional immaturity & $47(16.4)$ & $63(34.2)$ & 0.0005 \\
\hline Hypoxic-ischemic brain damage & $51(17.8)$ & $58(31.5)$ & 0.002 \\
\hline Premature newborns & $18(6.3)$ & $20(10.9)$ & 0.1 \\
\hline
\end{tabular}


The decrease in compensatory resources of pregnant women with "infect anemia" explained a three-fold increase in the frequency of infectious and inflammatory diseases (omphalitis, conjunctivitis, dacryocystitis, vesiculopustulosis) $(P=0.001)$. Signs of morphofunctional immaturity were detected in almost half of newborns in the ACD group, and half as often in the IDA group $(P=0.0005)$.

Hypoxic-ischemic damage to the central nervous system of newborns was noted more often in the group with "infect anemia" - almost one and a half times. High perinatal morbidity among women with anemia is caused by chronic hypoxia, which reflects morphofunctional failure of the placenta. ${ }^{(27,31)}$ Obviously, unfavorable antenatal conditions for fetal development among pregnant women with anemia are determined by the underdevelopment of terminal placental villi ${ }^{(29)}$ and their dystrophic changes.

The degree of dysregulation of the processes of cell growth and metabolism in the fetoplacental system differs depending on the genesis of anemia. Plastic deficiency is the starting point of the violation of the molecular mechanisms of protein biosynthesis in the placenta of pregnant women with anemia, being more vivid in "infect anemia." The "crisis" of placental angiogenesis in ACD determines the worst perinatal outcomes, due to damaging effects with the development of molecular-cellular "stress" in the mother-placenta-fetus system from the early stages of embryogenesis. Increased production of LPO markers corresponds to a violation of redox processes and biochemical reactions in the mitochondrial respiratory chain. ${ }^{(32)}$

Assessment of metabolism among pregnant women with anemia will make it possible to diagnose the degree of compensation for circulatory hypoxic disorders in the motherplacenta-fetus system.

Improving treatment and diagnostic approaches to pregnant women with anemia involves expanding the scope of examination (CRP, pro- and antioxidant defense factors) in groups with high infectious risk in order to identify markers of latent and subclinical infectious and inflammatory diseases. Significant adaptive homeostatic changes (oxidative stress on the background of an inflammatory response) among ACD women confirm the possibility of predicting adverse perinatal outcomes.

Early pathogenetic therapy will limit the degree of metabolic disorders among pregnant women with anemia, compensating for the consequences of abnormal placentation, and, therefore of perinatal morbidity.

\section{Competing Interests}

The authors declare that they have no competing interests.

\section{References}

1. Auerbach M, Georgieff MK. Guidelines for iron deficiency in pregnancy: hope abounds: Commentary to accompany: UK guidelines on the management of iron deficiency in pregnancy. Br J Haematol. 2020;188(6):814-816. doi:10.1111/ bjh. 16220
2. Vásquez-Velásquez C, Gonzales GF. Situación mundial de la anemia en gestantes [Global situation of anemia in pregnant women]. Nutr Hosp. 2019;36(4):996-997. doi:10.20960/ nh.02712. [Article in Spanish].

3. Sun D, McLeod A, Gandhi S, Malinowski AK, Shehata N. Anemia in Pregnancy: A Pragmatic Approach. Obstet Gynecol Surv. 2017;72(12):730-737. doi:10.1097/ OGX.0000000000000510

4. Pavord S, Daru J, Prasannan N, et al. UK guidelines on the management of iron deficiency in pregnancy. Br J Haematol. 2020;188(6):819-830. doi:10.1111/bjh.16221

5. Apresyan SV. Pregnancy and childbirth in extragenital diseases. In Radzinsky VE editor. M.: GEOTAR-Media; 2015, $536 \mathrm{pp}$.

6. Rukavitsyn OA. [Anemia of chronic diseases: actual aspects of diagnosis and treatment]. Clinical Oncohematology. 2012;5(4):296-304.[Article in Russian].

7. Rahman MM, Abe SK, Rahman MS, et al. Maternal anemia and risk of adverse birth and health outcomes in lowand middle-income countries: systematic review and metaanalysis. Am J Clin Nutr. 2016;103(2):495-504. doi:10.3945/ ajen.115.107896

8. Parks S, Hoffman MK, Goudar SS, et al. Maternal anaemia and maternal, fetal, and neonatal outcomes in a prospective cohort study in India and Pakistan. BJOG. 2019;126(6):737-743. doi:10.1111/1471-0528.15585

9. Achebe MM, Gafter-Gvili A. How I treat anemia in pregnancy: iron, cobalamin, and folate. Blood. 2017;129(8):940-949. doi:10.1182/blood-2016-08-672246

10. Rabindrakumar MSK, Pujitha Wickramasinghe V, Gooneratne L, Arambepola C, Senanayake H, Thoradeniya $\mathrm{T}$. The role of haematological indices in predicting early iron deficiency among pregnant women in an urban area of Sri Lanka. BMC Hematol. 2018;18:37. Published 2018 Dec 22. doi:10.1186/s12878-018-0131-2

11. Tayupova IM. [Medical and social aspects of iron deficiency anemia during pregnancy]. Vestnik Bashkirsk Universiteta. 2015;(3). URL: https://cyberleninka.ru/article/n/ mediko-sotsialnye-aspekty-zhelezodefitsitnoy-anemii-vovremya-beremennosti [Article in Russian].

12. Kæstel P, Aaby P, Ritz C, Friis H. Markers of iron status are associated with stage of pregnancy and acute-phase response, but not with parity among pregnant women in GuineaBissau. Br J Nutr. 2015;114(7):1072-1079. doi:10.1017/ S0007114515001993

13. Otto JM, Plumb JOM, Clissold E, et al. Hemoglobin concentration, total hemoglobin mass and plasma volume in patients: implications for anemia. Haematologica.2017;102(9):1477-1485. doi:10.3324/ haematol.2017.169680

14. Al-Gubory KH, Fowler PA, Garrel C. The roles of cellular reactive oxygen species, oxidative stress and antioxidants in pregnancy outcomes. Int J Biochem Cell Biol. 2010;42(10):1634-1650. doi:10.1016/j.biocel.2010.06.001

15. Harris C, Hansen JM. Oxidative stress, thiols, and redox profiles. Methods Mol Biol. 2012;889:325-346. doi:10.1007/978-1-61779-867-2 21

16. Burton GJ, Jauniaux E. Oxidative stress. Best Pract Res Clin Obstet Gynaecol. 2011;25(3):287-299. doi:10.1016/j. bpobgyn.2010.10.016

17. Agarwal A, Gupta S, Sharma RK. Role of oxidative stress in female reproduction. Reprod Biol Endocrinol. 2005;3:28. Published 2005 Jul 14. doi:10.1186/1477-7827-3-28 
18. Devrim E, Tarhan I, Ergüder IB, Durak I. Oxidant/ antioxidant status of placenta, blood, and cord blood samples from pregnant women supplemented with iron. J Soc Gynecol Investig. 2006;13(7):502-505. doi:10.1016/j.jsgi.2006.07.004 19. Choudhury N, Aimone A, Hyder SM, Zlotkin SH. Relative efficacy of micronutrient powders versus iron-folic acid tablets in controlling anemia in women in the second trimester of pregnancy. Food Nutr Bull. 2012;33(2):142-149. doi: $10.1177 / 156482651203300208$

20. Okhotnikova EN, Poonochnaya EV. [Anemia in chronic diseases]. Klin Immunol Allergol Infektolog. 2012;(5/6):2224. [Article in Russian].

21. Garcia AC, Roschel H, Ramos S, Benatti FB. Iron supplementation and its association with the incidence of gestational diabetes mellitus. J Braz Soc Food Nutr. 2012;37:215-226.

22. Ruckavitsyn OA. Topical issues of diagnosis and treatment of anemia in chronic diseases. Clinical Oncohematology. 2012;5(4):296-304. [Article in Russian].

23. Lopez A, Cacoub P, Macdougall IC, Peyrin-Biroulet L. Iron deficiency anaemia. Lancet. 2016;387(10021):907-916. doi:10.1016/S0140-6736(15)60865-0

24. Suryanarayana R, Chandrappa M, Santhuram AN, Prathima S, Sheela SR. Prospective study on prevalence of anemia of pregnant women and its outcome: A community based study. J Family Med Prim Care. 2017;6(4):739-743. doi:10.4103/jfmpc.jfmpc_33_17

25. Mburu AS, Thurnham DI, Mwaniki DL, Muniu EM, Alumasa F, de Wagt A. The influence and benefits of controlling for inflammation on plasma ferritin and hemoglobin responses following a multi-micronutrient supplement in apparently healthy, HIV+ Kenyan adults. J Nutr. 2008;138(3):613-619. doi:10.1093/jn/138.3.613

26. Karlsson T. Evaluation of a competitive hepcidin ELISA assay in the differential diagnosis of iron deficiency anaemia with concurrent inflammation and anaemia of inflammation in elderly patients. J Inflamm (Lond). 2017;14:21. Published 2017 Sep 18. doi:10.1186/s12950-017-0166-3

27. Figueiredo ACMG, Gomes-Filho IS, Silva RB, et al. Maternal Anemia and Low Birth Weight: A Systematic Review and Meta-Analysis. Nutrients. 2018;10(5):601. Published 2018 May 12. doi:10.3390/nu10050601

28. Radzinsky VE, Orazmuradov AA. Pregnancy of early terms. From pregravid preparation to healthy gestation, 3rd ed. M., Status Praesens; 2018, 800 pp.

29. Lelic M, Bogdanovic G, Ramic S, Brkicevic E. Influence of maternal anemia during pregnancy on placenta and newborns. Med Arch. 2014;68(3):184-187. doi:10.5455/ medarh.2014.68.184-187

30. Stangret A, Wnuk A, Szewczyk G, Pyzlak M, Szukiewicz D. Maternal hemoglobin concentration and hematocrit values may affect fetus development by influencing placental angiogenesis. J Matern Fetal Neonatal Med. 2017;30(2):199-204. doi:10.3109/14767058.2016.1168395

31. Leal CA, Schetinger MR, Leal DB, Morsch VM, da Silva AS, Rezer JF, et al. Oxidative stress and antioxidant defenses in pregnant women. Redox Rep. 2011;16(6):230-236. doi:10. 1179/1351000211Y.0000000013

32. Haider BA, Olofin I, Wang M, et al. Anaemia, prenatal iron use, and risk of adverse pregnancy outcomes: systematic review and meta-analysis. BMJ. 2013;346:f3443. Published 2013 Jun 21. doi:10.1136/bmj.f3443. 